\title{
Measurement of Reinforcement Corrosion in Concrete Adopting Ultrasonic Tests and Artificial Neural Network
}

\author{
Yidong $\mathrm{Xu}^{\mathrm{a}}$, Ruoyu Jin ${ }^{\mathrm{b}, *}$ \\ a Ningbo Institute of Technology, Zhejiang University, Ningbo 315100, China; \\ b School of Environment and Technology, University of Brighton, Cockcroft Building 616, Lewes Road, \\ Brighton, U.K., BN2 4GJ
}

\begin{abstract}
Limited research has been performed in testing and measuring the reinforcement corrosion levels using non-destructive tests. This research applied ultrasonic-based non-destructive test and artificial neural network to the diagnosis and prediction of rebar's non-uniform corrosion-induced damage within reinforced concrete members. Ultrasonic velocities were tested by applying ultrasonic to reinforced concrete prisms before and after the rebar corrosion. Input parameters including concrete strength, ultrasonic velocity, and the specimen dimension-related variable were used for the prediction of reinforcement corrosion level adopting artificial neural network models. Using totally 50 experimental observations, Radial Basis Function-based model was found with higher accuracy in predicting corrosion levels compared to Back Propagation-based model. This study leads to future research in high-accuracy non-destructive measurement of reinforcement corrosion in concrete.
\end{abstract}

Keywords: Reinforcement corrosion; reinforced concrete; non-destructive test; artificial neural network

\section{Introduction}

Concrete structural damage due to reinforcement corrosion is not uncommon and could be significant [1]. For example, chloride-induced durability problems shorten the service life of concrete structures [2]. The durability of concrete materials under chloride penetration 
requires particular attention [3]. However, reinforcement corrosion is not easily noticed. How to identify and measure the rebar corrosion within reinforced concrete structure remains a key issue in the concrete durability research. The commonly adopted non-destructive test approaches for the measurement include half-cell potential method [4] and concrete resistivity method (e.g, Wenner Four-Electrode Method [5]). These existing methods have their own advantages of being easy to operate for on-site tests with simple detection facility. However, both methods can only be used for the probability analysis of rebar corrosion within concrete but are unable to quantify the corrosion level or the corrosion-induced damage, especially for the non-uniform corrosion-induced damage within reinforced concrete. A more effective approach to test the rebar corrosion level would be to separate the rebar from concrete and measure the shape and depth of rebar etch-pits. Nevertheless, the separation of rebar from concrete would cause further structural damage and hence being not feasible. Therefore, it cannot be widely applied. There is hence an urgent need of developing a more applicable and practical measurement technology for the non-destructive test of rebar corrosion within concrete structures.

Ultrasonic measurement can be used to test concrete mechanical properties and internal defects through the elastic wave signals sent to concrete structures. The ultrasonic test implemented in concrete structure is based on the artificial method to generate elastic wave signals, which contains the information of propagation time (or speed), amplitude and frequency. The concrete structure is elastic-viscoplastic, with variations of acoustic impedance among its internal interfaces. The ultrasonic waves have strong reflection, scattering, diffraction, absorption, and waveform distortion when passing through the concrete structure. By extracting the information carried out in the signals and performing inversion analysis, the data of mechanical properties and defect distribution of materials and structures can be obtained. 
Huygens-Fresnel Principle [6] can be applied in supporting the ultrasonic measurement by comparing the defect size and the wave length, as the wave path would be different depending on the defect size within concrete structures. The predication of concrete strength by integrating ultrasonic wave and artificial neural network (ANN) has been performed in some existing studies such as Trtnik et al. [7] and Kewalramani and Gupta [8]. However, there has not been sufficient research on applying ultrasonic wave in measuring the rebar corrosion within concrete structures. ANN, as one of the data mining methods that have been widely applied in estimating concrete mechanical properties (e.g., strength) in existing studies such as Chithra et al. [9], Omran et al. [10], Sadowski et al. [11], Wang et al. [12], Wang et al. [13], has not been sufficiently used in the prediction of corrosion level of reinforcement in concrete.

Non-destructive tests have been applied in the test and evaluation of properties of construction materials, such as bond between concrete layers [11], compressive strength [12], and other types of mechanical properties [15]. However, limited studies have been performed in applying non-destructive tests to measure reinforcement corrosion level in concrete members in a quantitative approach. Yeih and Huang [16] adopted ultrasonic testing for the non-destructive detection of concrete reinforcement corrosion, and found certain correlation between the reduction of ultrasonic amplitude and the electrochemical parameters of corrosion. Continued from the research of Yeih and Huang [16], this study aims to apply the ultrasonic test in measuring the corrosion level of non-uniform surfaces of rebar, and to evaluate the accuracy of ultrasonic test-based measurement on reinforcement corrosion level. Radial Basis Function (RBF)-based and Back Propagation (BP)-based models are applied and to be compared of their accuracies in the prediction. The study serves as the initial exploration of non-destructive tests of rebar corrosion level in non-uniform surfaces, leading to further research in establishing 
the non-destructive test procedure in measuring steel corrosion within reinforced concrete structures.

\section{Experimental program}

\subsection{Linking reinforcement corrosion level to ultrasonic velocity}

The corrosion process of reinforced concrete was defined by Zhao and Jin [17] in terms of three stages, namely: 1) the first stage of free expansion of rust, in which the steel corrosion products fill the rebar/concrete interface voids; 2) tensile stress within concrete cover, in which the concrete cover starts cracking; and 3) cracking within concrete cover, when the cracking continues to be filled with the rust products. Empirical formulas have been established to estimate the rebar corrosion level in concrete structures. Zhao and Jin [17, 18] further proposed empirical formulas to estimate the corrosion depth of reinforcement. Zhao et al [19] used stereoscopic microscope to observe the seriously corroded layer and found that the corrosion depth was not more than $500 \mu m$. Following Huygens-Fresnel Principle [3], when the corrosion layer size is smaller than the wavelength, the ultrasound would diffract, resulting in a longer receiver signal. In addition, since the acoustic impedance of the air is far lower than that of concrete, sound energy would decrease and the sound duration would increase resulting from the reflecting and scattering of pulse wave at the corrosion surface. Therefore, it is feasible to detect the corrosion level of reinforcement in concrete according to the ultrasonic velocity. The effect of test specimen size described in Fig. 1 in ultrasonic velocity was studied by Zhang and Qiu [20]. 


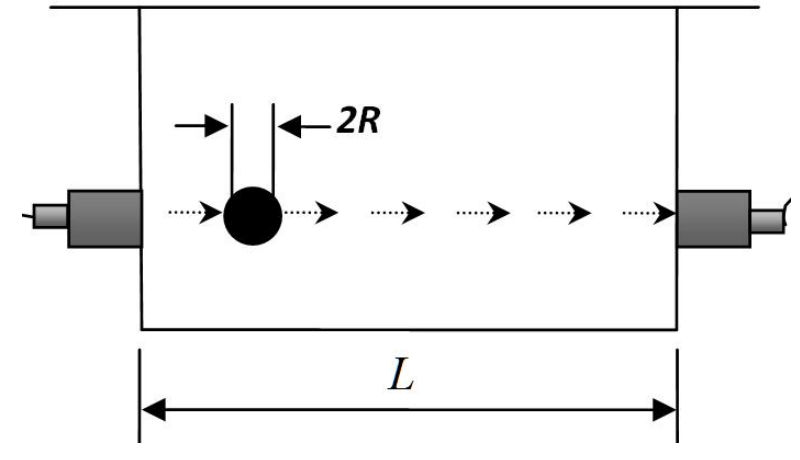

(a) Before corrosion

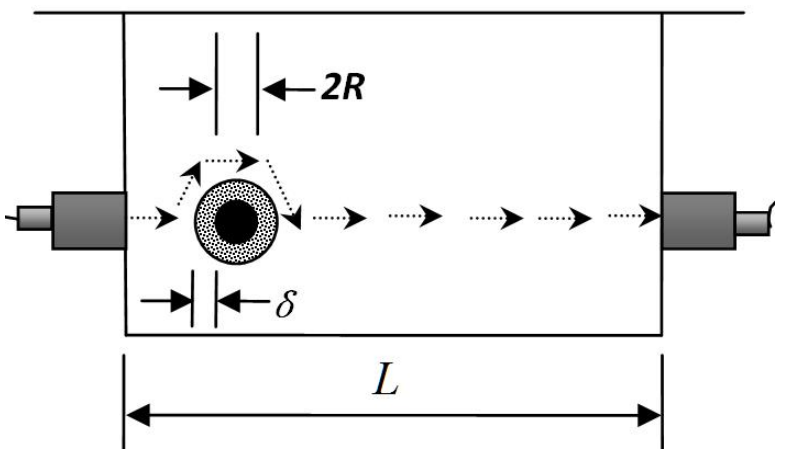

(b) After corrosion

Fig.1. Ultrasonic propagation path in reinforced concrete

As illustrated in Fig.1, $R$ denotes the rebar radius, $\delta$ represents the depth of steel corrosion layer, and $L$ is the distance between the emission transducer and receiving transducer within the ultrasonic generator. It was previously found by Zhang and Qiu [20] that under the same ultrasonic velocity in concrete, the effect of rebar in ultrasonic velocity would be reduced as the ratio of rebar to the test distance (denoted as $2 R / L$ ) decreases. When this ratios is lower then $1 / 12$, the effect of rebar size could be ignored according to Zhang and Qiu [20].

\subsection{Experimental set-up}

Four different types of reinforced concrete specimens, namely $C 20, C 25, C 30$, and $C 35$, were prepared by Gutetong Company from Ningbo China. The mix design details of these four types of specimens are provided in Table 1.

Table 1. Mix design details of four different concrete specimens in this study

\begin{tabular}{|c|c|c|c|c|c|c|c|c|}
\hline $\begin{array}{c}\text { Specimen } \\
\text { Type }\end{array}$ & $\begin{array}{c}\text { Portland } \\
\text { Cement } \\
\left(\mathrm{kg} / \mathrm{m}^{3}\right)\end{array}$ & $\begin{array}{c}\text { Fly ash } \\
\left(\mathrm{kg} / \mathrm{m}^{3}\right)\end{array}$ & $\begin{array}{c}\text { Granulated } \\
\text { blast furnace } \\
\text { slag } \\
\left(\mathrm{kg} / \mathrm{m}^{3}\right)\end{array}$ & $\begin{array}{c}\text { Sand } \\
\left(\mathrm{kg} / \mathrm{m}^{3}\right)\end{array}$ & $\begin{array}{c}\text { Coarse } \\
\text { aggregate } \\
\left(\mathrm{kg} / \mathrm{m}^{3}\right)\end{array}$ & $\begin{array}{c}\text { Water } \\
\left(\mathrm{kg} / \mathrm{m}^{3}\right)\end{array}$ & $\begin{array}{c}\text { Water } \\
\text { reducer } \\
\left(\mathrm{kg} / \mathrm{m}^{3}\right)\end{array}$ & $\begin{array}{c}\text { Slump } \\
(\mathrm{mm})\end{array}$ \\
\hline $\mathrm{C} 20$ & 182 & 112 & 26 & 757 & 1045 & 195 & 3.52 & 150 \\
\hline $\mathrm{C} 25$ & 202 & 87 & 47 & 762 & 1052 & 185 & 4.04 & 150 \\
\hline C30 & 220 & 83 & 58 & 736 & 1059 & 180 & 4.50 & 150 \\
\hline C35 & 245 & 78 & 66 & 695 & 1086 & 175 & 5.06 & 150 \\
\hline
\end{tabular}


Totally 50 groups of concrete specimens were cast, among them 44 were prisms sized at $100 \mathrm{~mm} \times 100 \mathrm{~mm} \times 400 \mathrm{~mm}$, and six of them being prisms sized at $150 \mathrm{~mm} \times 150 \mathrm{~mm} \times 550 \mathrm{~mm}$, each prism was embedded with a hot-rolled round steel rebar with the diameter of $12 \mathrm{~mm}$. Cured at the standard laboratory condition for 28 days, specimens were placed in the chloride salt and stray current condition to reach different levels of rebar corrosion. Specifically, two types of corrosion tests were adopted in this study, namely chlorine salt wet-dry cycle and stray current method. In the chlorine salt wet-dry cycle approach, specimens after 28 days' standard curing were soaked and placed in 5\% sodium chloride solution for 12 hours, and then oven dried in the temperature of $50 \pm 1{ }^{\circ} \mathrm{C}$ for another 12 hours. This was counted as one wet-dry cycle. The same cycles were repeated to corrode reinforcement in the chloride salt environment; in the stray current condition, concrete specimens after the same 28 days' standard curing were buried in the 5\%-sodium-chloride-wetted sand. Rebar was then used as the anode with copper bars as cathodes. They were electrified with a DC power supply to create rebar corrosion in the stray current conditions.

The NM-4A type of non-metallic instrument was adopted in this study to test the ultrasonic velocity within the concrete specimen. To prevent the ultrasonic velocity being affecting by the variation of specimens' moisture contents, each specimen was stored indoor under constant room temperature and dried for three days. Each specimen's longitudinal surface was set up with nine test areas. The average ultrasonic velocity was calculated from the nine test areas. Test details, including specimen sections and the nine test zones are described in Fig. 2. The test procedure is illustrated in Fig.3.

Fig.2. Reinforced concrete specimen for ultrasonic tests with details of test specimens (Size units $/ \mathrm{mm}$ ) 

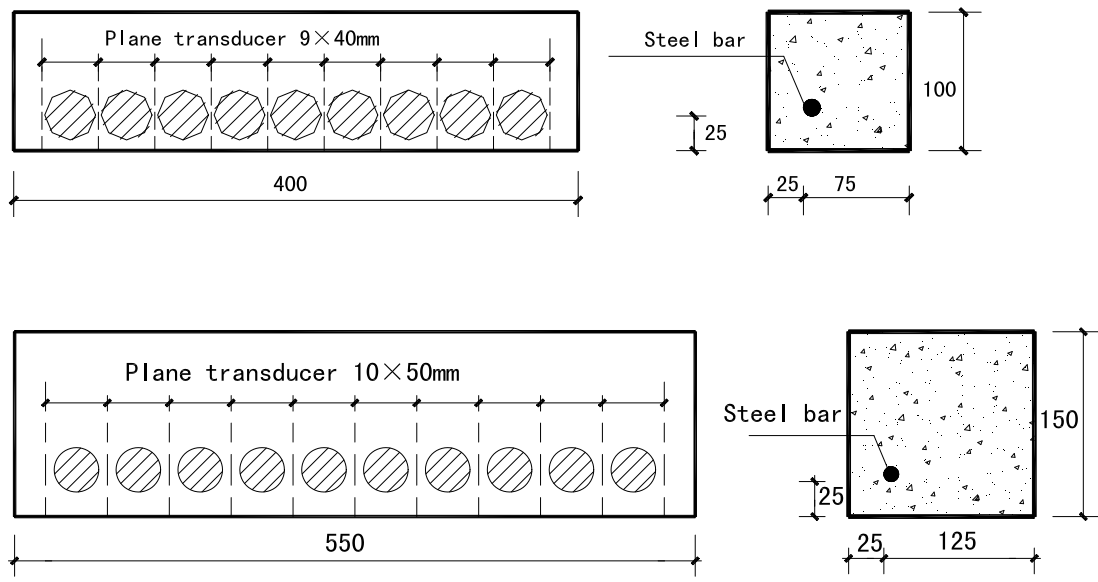

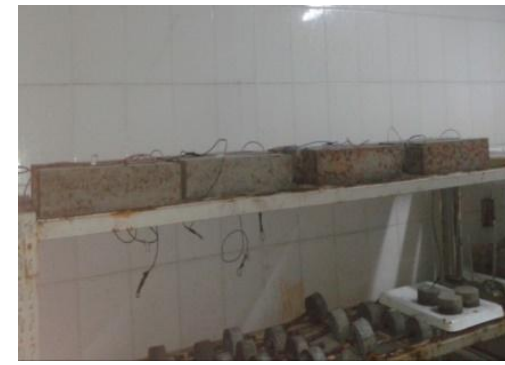

(a) Concrete curing

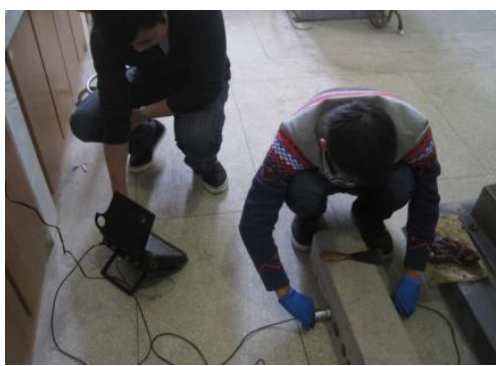

(d) Ultrasonic test for prisms sized at $150 \mathrm{~mm} \times 150 \mathrm{~mm} \times 550 \mathrm{~mm}$

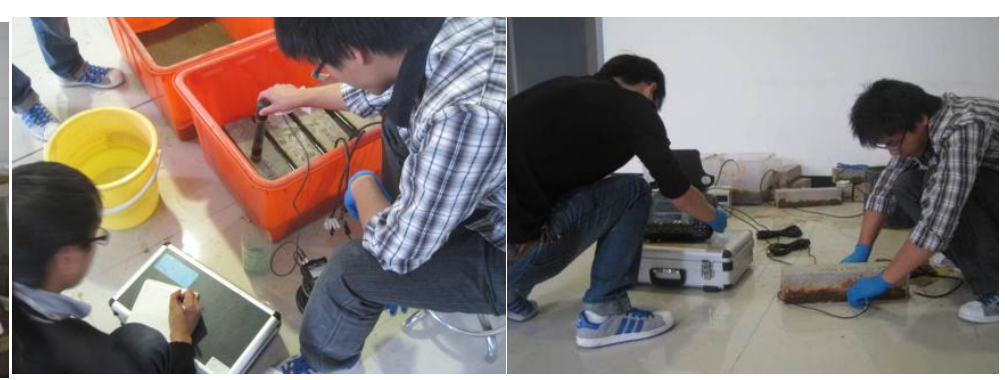

(b) Half-cell test

(c) Ultrasonic test for prisms sized at $100 \mathrm{~mm} \times 100 \mathrm{~mm} \times 400 \mathrm{~mm}$

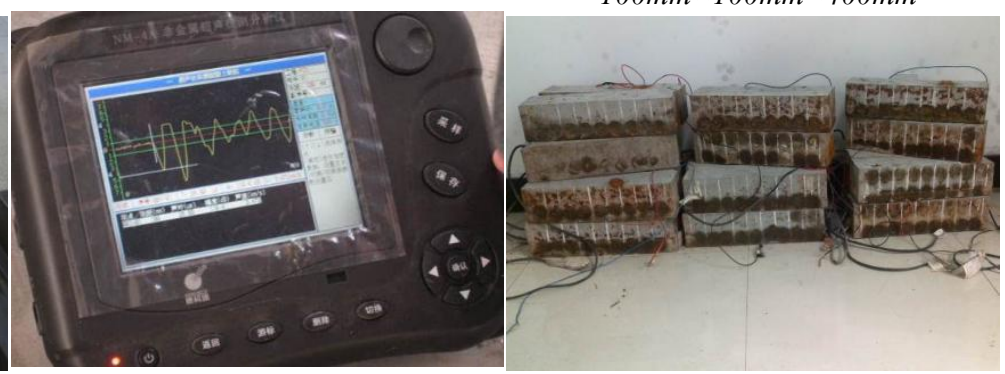

(e) NM-4A type of non-metallic ultrasonic instrument (f) Specimens after testing

Fig.3. Schematic illustration of ultrasonic testing

Before the ultrasonic test had been performed in concrete specimen, the effect of concrete moisture content on ultrasonic velocity was examined. Mix design targeting on C30 ordinary concrete was adopted to cast two standard prisms, with the dimension at $100 \mathrm{~mm} \times 100 \mathrm{~mm} \times 400 \mathrm{~mm}$. Cured at the standard condition on Day 28 , the reinforced prism was connected to electrical circuits to achieve different degrees of corrosion severity. Later, following the procedure described by Liu et al. [21], the corroded specimens were immersed 
in water for three days to reach full saturation. The saturated specimens were then removed from water, surface dried, and weighted. The specimens were then put in ovens to be gradually dried with lower moisture content. After each drying period, the specimen was removed from the oven, weighted, and retested of the ultrasonic velocity until it reached its constant weight when fully internally dried. The test setup is illustrated in Fig.4.

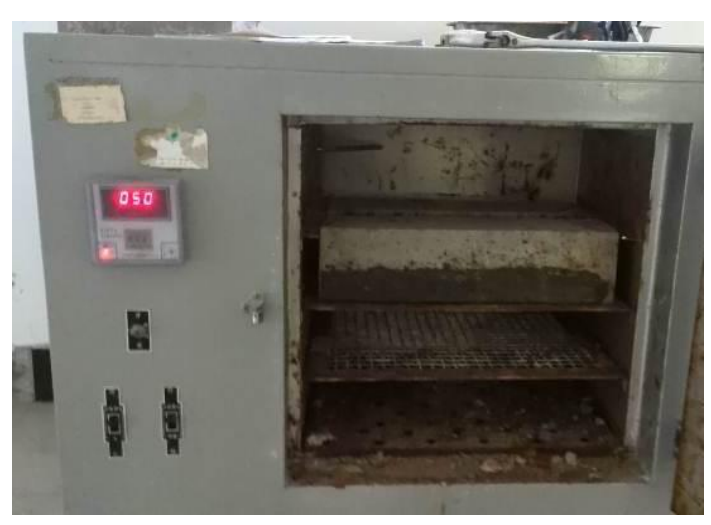

(a) Specimens being dried

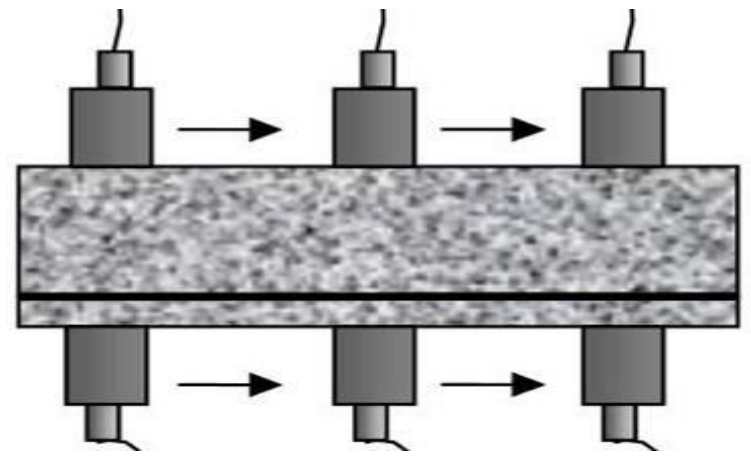

(b) Schematic illustration of ultrasonic testing

Fig.4. Test setup to studying the influence of moisture content on ultrasonic velocity

Data obtained from the test setup described in Fig.4 would then allow the correlation analysis between moisture content and the average ultrasonic velocity.

\subsection{Application of artificial neural network to predicting rebar corrosion}

Artificial neural network (ANN) was applied in this research to analyzing the rebar corrosion, based on the three following features of ANN [22]: 1) it has strong self-adaptability and is able to capture the corrosion-caused damage in concrete members; 2) it is able to store the damage-related information in the learning stage and compare the predicted data with the measured outcomes; 3) it is robust with its non-linear mapping capacity to establish the relationship between the rust damage related value and the non-destructive parameters. In this study, ANN was modeled using the NeuroSolutions [23] as the tool. 
The Back Propagation (BP) and Radial Basis Function (RBF) were the two ANN models that were adopted in this research to link the non-destructive parameters to corrosion levels of rebar in concrete prisms.

BP has been widely applied in the field of civil engineering [24-27]. The topology structure of BP-based network can be described in Fig.5.

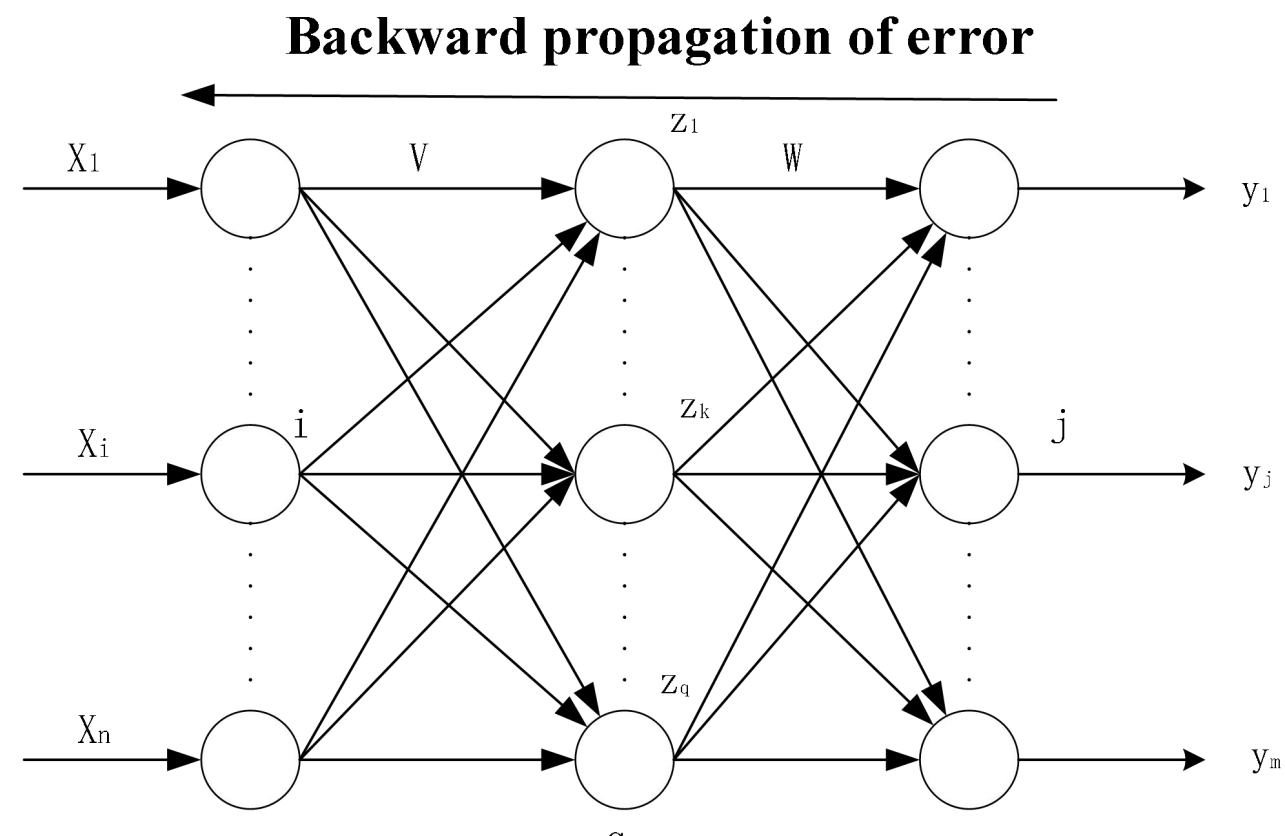

n

q

m

\section{Input Hidden layer Output}

\section{Positive information dissemination}

Fig.5. topology structure of BP neural network

As displayed in Fig.5, the data samples start from the input layers, passing the hidden layer until they reach the output layer. In Fig.4, $\omega_{i j}$ and $\omega_{i j}$ represent the connection weightings when data is moving forward from the input layer to hidden layer, and from the hidden layer to the output layer respectively. During the learning and training process, the error would be passed backwards through hidden layer to input layer if the actual output value does not match the expected value. Then the error is spreading to all cells in the input layer illustrated in Fig.5. The error signal serves as a basis for modifying the weighing of 
each cell. The weightings will be adjusted through a new cycle by passing the data forward from input to output layers. This kind of cycle can be reprocessed until the error is reduced to a tolerable level, or the learning process has completed certain specified number of cycles. Detailed process of running BP-based models can be found in Buscema [28] and Hecht-Nielsen [29].

RBF's topology structure can be described in Fig.6. Differing from BP, the input layer in RBF only passes information, with the connection weighting at 1.0. The radial basis function is incorporated in the hidden layer. Linear weightings are adjusted in the output layer. The steps to perform RBF-based network can be found in Billings et al. [30] and Chen et al. [31].

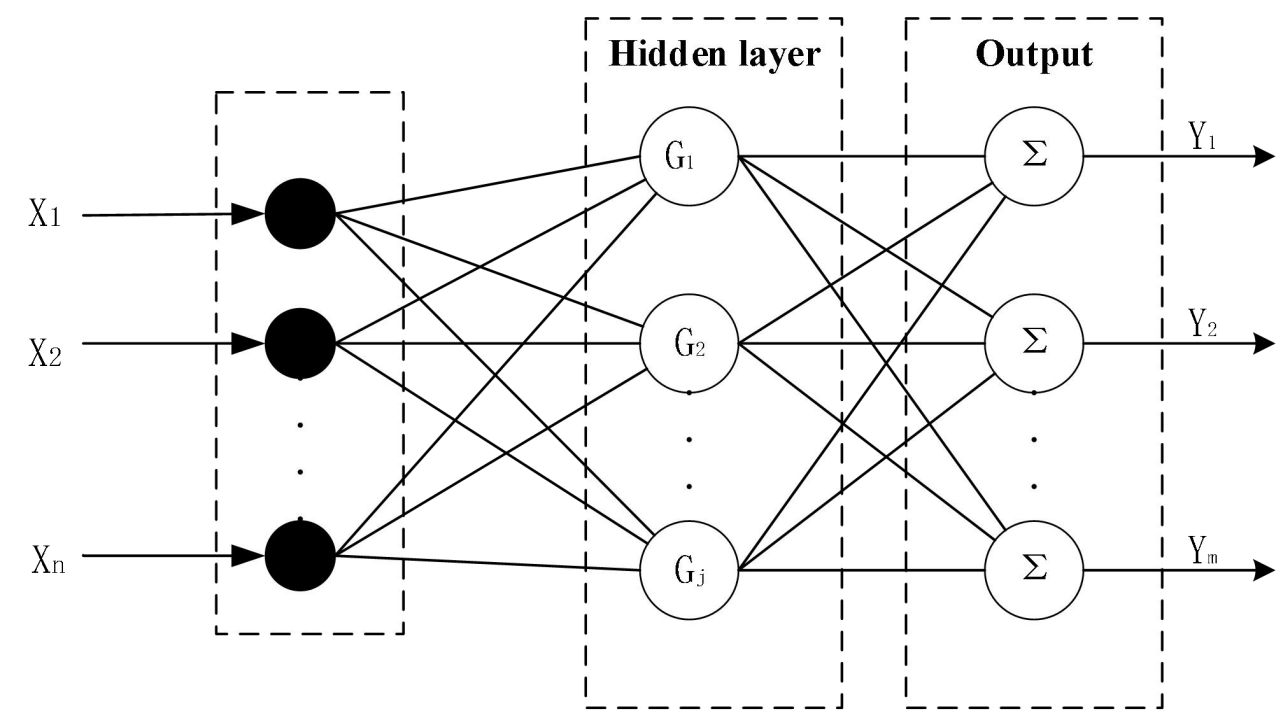

Fig.6. topology structure of RBF neural network

Although RBF has not been widely applied in predicting steel corrosion levels, certain relevant existing studies can be found, such as Chou et al. [32] and Pai et al. [33].

The main difference between BP and RBF lies in that BP model utilizes the S-type hyperbolic function in its hidden layer. In comparison, RBF is a non-linear network, with its hidden layer utilizing Gaussian function. Both BP and RBF were adopted in the prediction of rebar corrosion levels in this research. Both types of ANN models contain the three layers 
(i.e., input, hidden, and output layers). Applied in the predication of rebar corrosion levels, three nodes were included in the input layer for both models, namely compressive strength of concrete specimens $\left(X_{I}\right)$, average ultrasonic velocity $\left(X_{2}\right)$, and the ratio (i.e., $\left.2 R / L\right)$ of rebar diameter to test distance illustrated in Fig.1. Four treatment nodes were set in the hidden layer. Rebar corrosion level was set as the single node in the output layer. The Levenberg-Marquardt algorithm was adopted in the data training. The maximum training time was set at 1,000. After the networks were established, data sample could be used for the training. The data sample was divided into training sample and the cross-validation sample. When the training was complete, the error was reduced and eventually approached 0 , and corresponding weightings were stored automatically.

\section{Results and discussion}

\subsection{Laboratory observations}

Under the laboratory condition, the interfaces between concrete and corroded reinforcements were observed as presented in Fig.7.

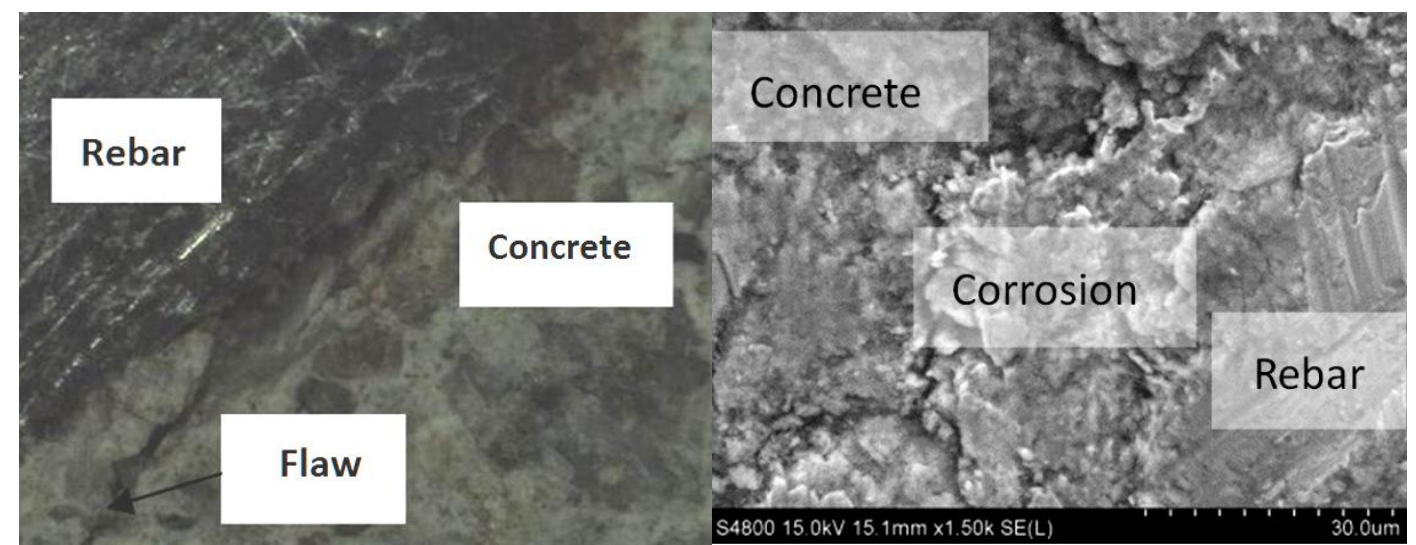

Fig.7. Defects of interfaces between corroded reinforcement and concrete

The development of steel corrosion led to defects in the interfaces between reinforcement and concrete as shown in Fig.7. To further identify the defect size of corrosion layers formed in reinforced concrete prisms, the element distribution of the corrosion area was analyzed 
adopting scanning electron microscopy (SEM) and electron probe. Adopting C30 specimen as the showcase, the analysis is illustrated in Fig.8.
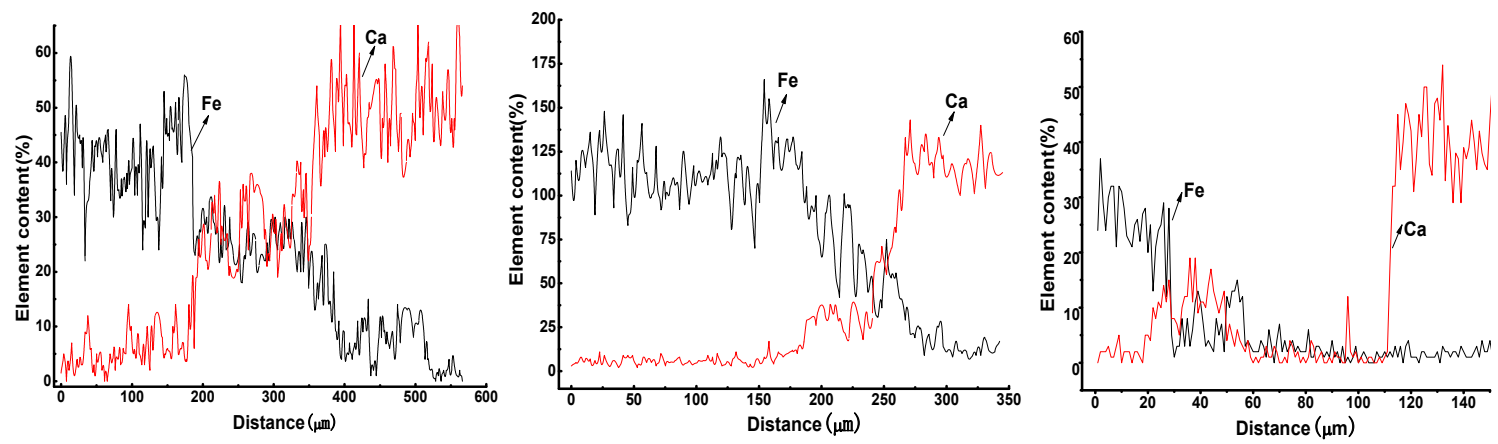

Fig.8. Linear SEM/EDS analysis of chemical elements in corrosion layer

The black-colored line denoted with $\mathrm{Fe}$ in Fig.8 represents the rebar, and the red-colored line denoted with $\mathrm{Ca}$ is concrete. Both lines underwent sudden sharp drops of their element content as it can be seen in Fig.8, indicating the occurrence of corrosion. The length of the overlapping zones of the two lines shows the corrosion depth. It is found from Fig.8 that the corrosion depth was between $80 \mu m \sim 200 \mu m$, below the maximum depth of seriously corroded rebar at $500 \mu m$ according to Zhao et al. [19].

\subsection{Effects of moisture contents in ultrasonic velocity}

The experimental data of water content corresponding to the ultrasonic velocity is described in Fig.9. Various moisture contents ranging from 0 to $2.5 \%$ in concrete were included. 


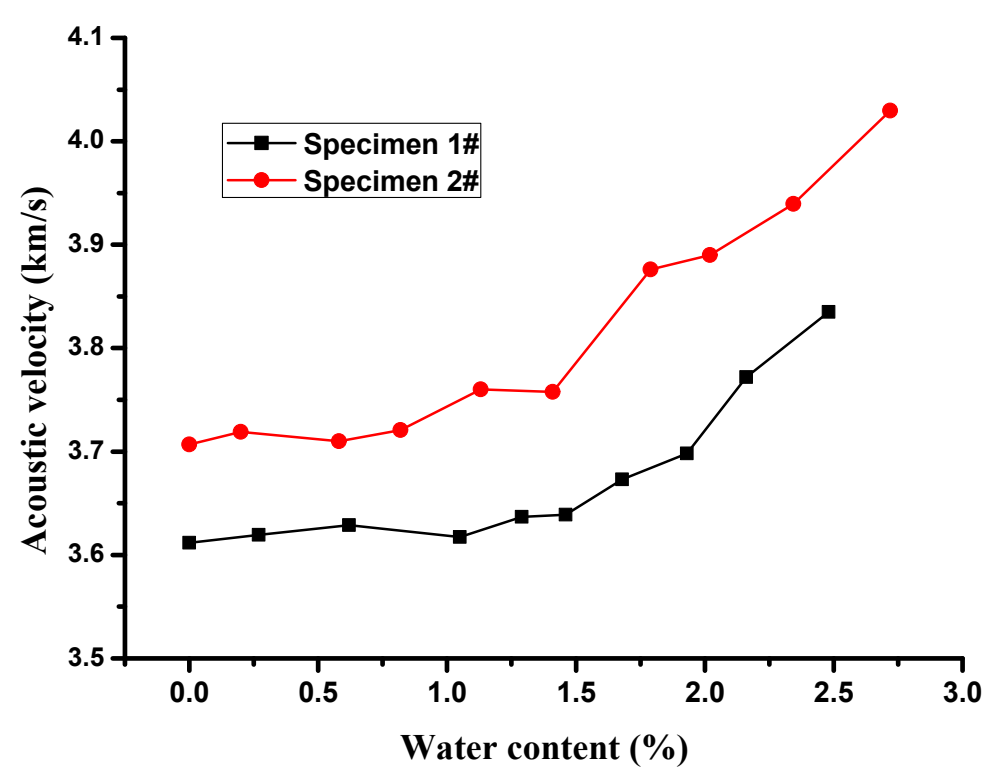

Fig.9. Relationship between ultrasonic velocity and moisture content

Specimens 1 and 2 in Fig.9 represent two different corrosion levels of reinforcement. It can be found from Fig.9 that under both corrosion levels, ultrasonic velocity would not be significantly affected when the moisture content in concrete is not higher than $1.5 \%$. As the moisture content increases from $1.5 \%$ in concrete specimens, the ultrasonic velocity would grow more significantly to be $8 \%$ higher compared to that when concrete is fully dried. The effect of moisture content in ultrasonic velocity could be due to the heterogeneous feature of concrete structure. Voids and cracking in corroded concrete members are filled with air or moisture. The moisture content in concrete structure would affect the air percentage in concrete, resulting in the change of ultrasonic velocity. As ultrasonic wave travels significantly faster in liquids than in the air, it would be significantly increased when concrete cracking was filled with more moisture. The experimental tests indicated that the moisture content lower than $1.5 \%$ could be considered as dry condition when the moisture is not continuously or evenly distributed within concrete internal voids. As a result, the ultrasonic velocity would not be significantly changed. This initial study of moisture content's effect in ultrasonic velocity provides the threshold value that in conducting the ultrasonic tests within concrete structures, concrete should be kept dry with the moisture content below $1.5 \%$. 


\subsection{Ultrasonic test results}

Ultrasonic velocities were tested within different types of specimens under different corrosion levels before and after corrosion. Four typical types of recorded acoustic velocities along the nine locations within the same specimen are showcased in Fig.10.
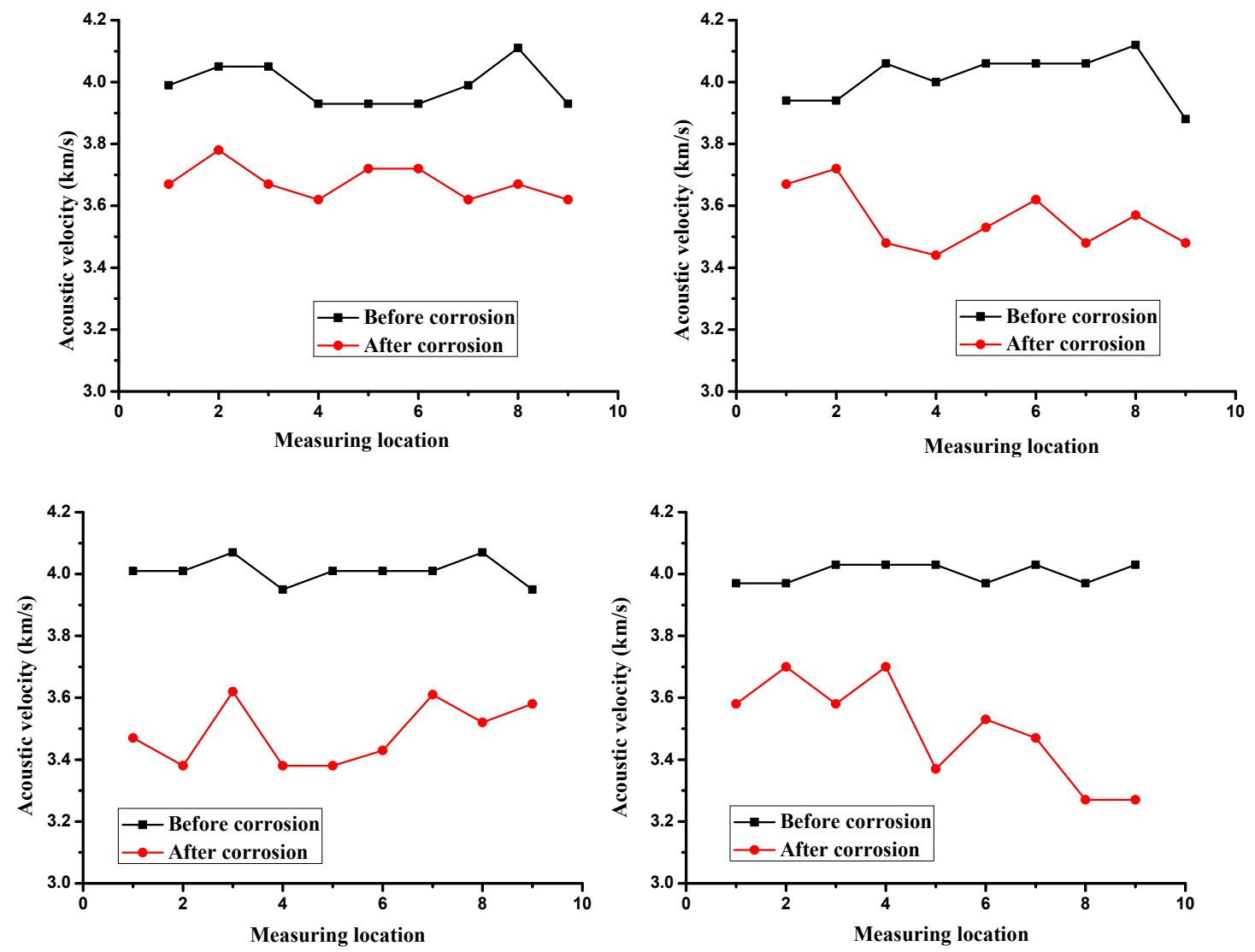

Fig.10. Comparison of ultrasonic velocities before and after corrosion

Fig.10 displays four examples representing different corrosion levels of reinforcement. All the four examples in Fig.10 demonstrate that ultrasonic velocity was significantly higher in concrete before rebar corrosion. The velocity tested at the nine different areas of the same specimen was generally stable with little variation before corrosion. After the rebar corrosion, the ultrasonic velocity was significantly reduced, and the nine tested velocities within the same concrete specimen had a larger variation. The variation of ultrasonic velocity could be explained by the micro-structure of the concrete specimen. The number and size of defects (e.g., pores and micro-cracks) within concrete structures are relatively small before rebar 
corrosion, and the ultrasonic wave would mainly be transmitted with high velocity in a stable way. Following the rebar corrosion, the corrosion products increase creating defects at the concrete-reinforcement interfaces as shown in Fig.11. The final corrosion force leads to concrete cracking and diffraction of ultrasonic wave. The reflection and scattering of ultrasonic waves would then result in significant reductions of velocity according to Wang et al. [34].

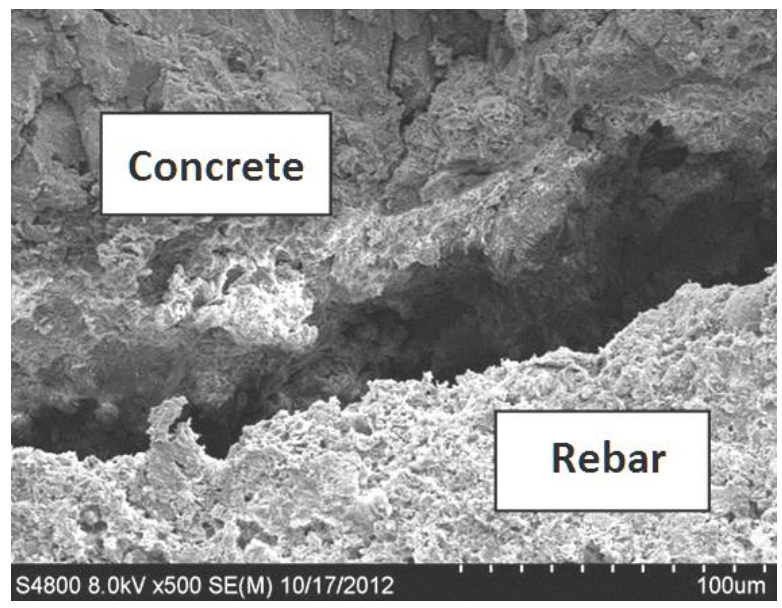

Fig. 11. Interface cracking of reinforced concrete due to corrosion expansion

\subsection{Results of applying ANN to predicting rebar corrosion rates}

Totally 50 observations were used as the data sample in applying BP and RBF models. Among them 45 observations were adopted as the training set, and the rest five were used as the cross-validation set. Fig.12 displays an example of data training.

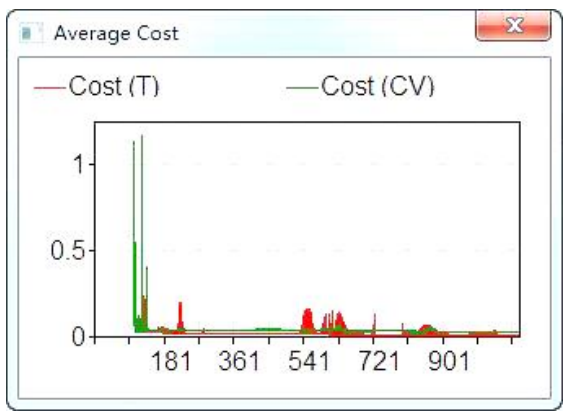

a) Learning curve

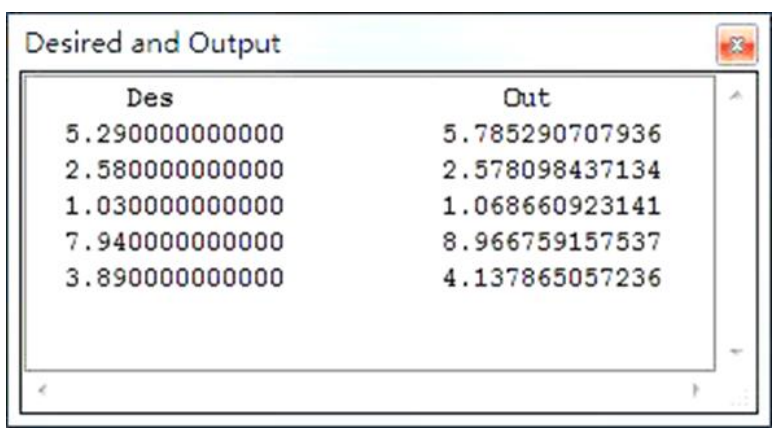

b) Comparing the desired and actual output corrosion rates

Fig.12. Learning curves and predicting the corrosion mass loss ratio of using RBF model 
The two ANN models were compared of their performance. Both models were able to complete the data training and predict the rebar corrosion level based on the three input parameters (i.e., $X_{1}, X_{2}$, and $X_{3}$ ), where $X_{1}$ stands for the design compressive strength pf concrete, $X_{2}$ is the average ultrasonic velocity within each observation sample, and $X_{3}$ means the ratio of rebar diameter to the test distance (denoted as $2 \mathrm{R} / \mathrm{L}$ ) as shown in Fig.1. The dependent variable (i.e., corrosion level) was measured by the reinforcement mass loss ratio as shown in Equ.(1).

$$
\mathrm{S}=\frac{\mathrm{m}_{\mathrm{o}}-\mathrm{m}_{1}}{\mathrm{~m}_{\mathrm{o}}} \times 100 \%
$$

where $S$ denotes the mass loss ratio of reinforcement, $\mathrm{m}_{0}$ is the mass of the originally non-corroded specimen, and $\mathrm{m}_{1}$ represents the mass of the corroded specimen after de-rusting. Upon the end of each ultrasonic test in this research, corroded reinforcements were washed using de-rusting solution to remove corrosion products after the corrosion process. The appearances of rebar before and after de-rusting are shown in Fig.13.
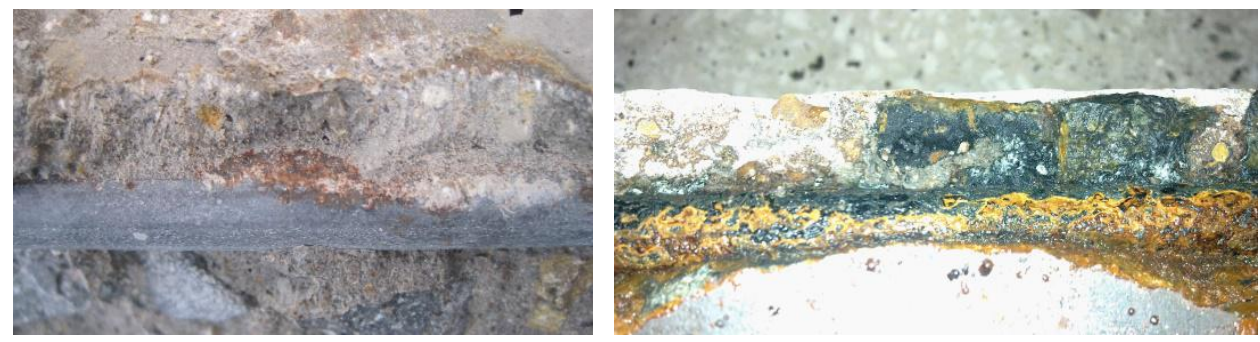

(a) Reinforcement before de-rusting

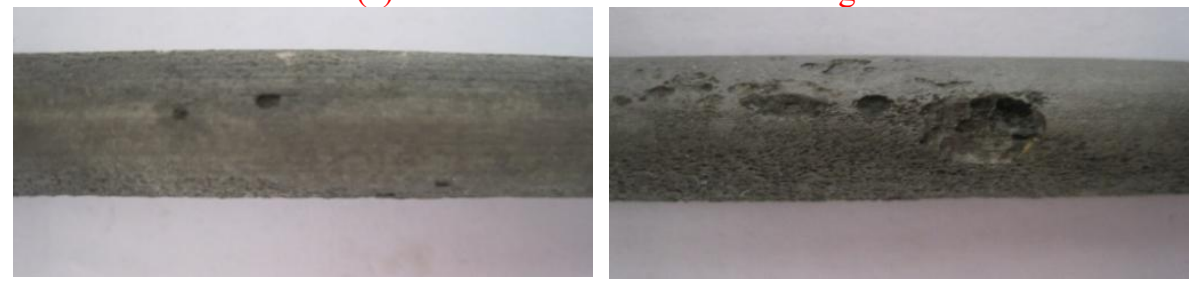

(b) Reinforcement after de-rusting

Fig.13. Images of reinforcement before and after the corrosion

The removal solution applied in the de-rusting of rebar was prepared by mixing $3 \%$ of hexamethylene tetramine with $97 \%$ of diluted hydrochloric acid by weight. The relative errors of prediction from the cross-validation sample are listed in Table 2. 
Table 2. Corrosion mass loss ratio predicted by neural networks

\begin{tabular}{cccccccccc}
\hline $\begin{array}{l}\text { Data } \\
\text { set }\end{array}$ & $X_{1}$ & $X_{2}$ & $X_{3}$ & $\begin{array}{l}Y \\
\text { (Observed) }\end{array}$ & $\begin{array}{c}Y \\
\text { (BP) }\end{array}$ & $\begin{array}{l}\text { Relative } \\
\text { error } / \%\end{array}$ & $Y$ (RBF) & $\begin{array}{l}\text { Relative } \\
\text { error } / \%\end{array}$ \\
\hline & 1 & C25 & 3.6220 & 0.12 & 5.29 & 5.36 & 1.32 & 5.79 & 9.45 \\
& C30 & 3.8723 & 0.12 & 2.58 & 1.82 & 29.46 & 2.58 & 0.00 \\
3 & C35 & 3.9920 & 0.12 & 1.03 & 1.05 & 1.94 & 1.07 & 3.88 \\
4 & C20 & 3.4557 & 0.12 & 7.94 & 8.30 & 4.53 & 8.97 & 12.97 \\
5 & C30 & 4.1580 & 0.08 & 3.89 & 2.69 & 30.85 & 4.14 & 6.43 \\
\hline
\end{tabular}

It can be found from Table 3 that the RBF model had a superior performance in terms of generally lower relative errors. Several significantly large relative errors were found in the validation sample adopting $\mathrm{BP}$, such as data set 2 and 5 related to $\mathrm{C} 30$. The comparison between $\mathrm{BP}$ and RBF showed that RBF had the lower standard error. Compared to BP, RBF could better detect the non-linear relationship between the input and output layers with an overall higher prediction accuracy, due to its own advantages in network structure, training algorithms, and usage of network resources, specifically:

1) BP network applied weightings from its input layer to the hidden layer. It is not easy to determine the number of hidden layer units in BP network. The network structure will not be changed once it is confirmed in the training process. In comparison, the RBF network utilizes the direct connection between its input and hidden layers, but weightings are applied between its hidden layer and the output layer. RBF is capable of adjusting the number of hidden layer units during the training.

2) theoretically, both BP and RBF models are capable of providing the non-linear prediction approach. However, they apply different functions with varied performance of approximation. BP network, with the S-shaped function as the transformation function, uses the approximation of the nonlinear mapping. The RBF network is a network derived from the regular theory. It uses the locally exponentially decaying Gaussian function to locally approximate the nonlinear mapping and has the best approximation Nature according to Zhang [35]. 
3) the determination of BP neural network weights and thresholds is directly determined by the sum of the squared deviations of each output node. The trained network can only be a compromise between different tasks, and the best effect cannot be achieved for one task. In comparison, the distribution of hidden layer units in RBF network can be decided according to the capacity, category and distribution of training samples. Based on the distribution of hidden layer units, the mapping relationship between input and output can be achieved by adjusting the mapping between the hidden layer's and output layer's units. The impact of different tasks is relatively small, and the network resources can be fully utilized.

It should be noted that the neural network models established in this study of non-destructive test in reinforced concrete specimens serve as initial references in predicting steel corrosion levels. Continuous data training will be performed as the sample size increases. The future work will focus on building a more comprehensive prediction system with more ANN models or data mining methods, as well as further improving the prediction performance.

\section{Conclusion}

This study aimed to adopt the ultrasonic test as the non-destructive approach in measuring the corrosion level of non-uniform surfaces of rebar within the reinforced concrete structure. Then the artificial neural network was applied in training the experimental data for the prediction of rebar corrosion level. Based on the experimental investigation and the neural network modeling, the following findings can be summarized:

(1) The rebar-concrete interface was observed using scanning electron microscopy (SEM) and electron probe. The corrosion depth in the reinforced prism was identified between $80 \mu m \sim 200 \mu m$; 
(2) The effect of water content in concrete specimens' ultrasonic velocity was studied before conducting the corrosion tests. It was identified that moisture content below $1.5 \%$ in concrete would not cause significant increases of ultrasonic velocity. Moisture content over $1.5 \%$ would cause more significant increase (i.e., up to $8 \%$ ) of ultrasonic velocity;

(3) Rebar corrosion would cause significant reductions in ultrasonic velocity in concrete specimens. Compared to the ultrasonic velocity before rebar corrosion, the ultrasonic velocity tested at different zones of the same concrete specimen also tended to vary more significantly. The larger variation of ultrasonic velocity after rebar corrosion was due to the micro-structural perspective in the concrete structure;

(4) two types of artificial neural network models (i.e., BP and RBF) were applied in predicting the rebar corrosion level based on 50 experimental observations. RBF was found outperforming BP in predicting the rebar corrosion level due to the smaller average relative error. The superior performance of RBF was described in comparison to BP in terms of network structure, training algorithm, and network resource usage.

The current study is limited in its data sample size and the types of neural network models. Future research would recruit a larger data sample and more neural models to further explore the application of artificial neural network and other data mining methods in predicting steel rebar's non-uniform corrosion-induced damage in reinforced concrete members. More future research needs to be performed to extend the current study, which only adopted a single rebar in the test specimen. The current study adopted the average velocity of nine test areas within the same specimen to estimate the overall corrosion level of reinforcement. But the current study can lead to future research if different test areas of the same specimen are recorded and input for data analytics. Overall, this research serves as the initial movement towards applying the ultrasonic test as one non-destructive method to estimate reinforcement corrosion level within concrete. 


\section{Acknowledgement}

The authors wish to acknowledge the financial support of National Natural Science Foundation of China (Grant No. 51778577), Zhejiang Provincial Natural Science Foundation (Grant No. LY15E080025 and Grant No. LY16E020014), and the Ningbo Natural Science Foundation (Grant No. 201601HJ-B01068).

\section{References}

[1] G.L. Feng, L.Y. Li, B.Kim B, Q.F..Liu, Multiphase modelling of ionic transport in cementitious materials with surface charges, Comput. Mater. Sci. 111(2016) 339-349.

[2] Q.F. Liu, G.L. Feng, J. Xia, J.Yang, L.Y.Li, Ionic transport features in concrete composites containing various shaped aggregates: a numerical study, Comp. Struc. 183(2018) 371-380.

[3] Z.Hu, L.X. Mao, J. Xia, J.B.Liu, J. Gao, J. Yang, Q.F. Liu, Five-phase modelling for effective diffusion coefficient of chlorides in recycled concrete. Magazine of Concrete Research.2017.

[4] M. Raupach, Half-cell potential measurements-Potential mapping on reinforced concrete structures.

[5]ASTM G57-06(2012), Standard Test Method for Field Measurement of Soil Resistivity Using the Wenner Four-Electrode Method, ASTM International, West Conshohocken, PA, 2012.

[6] Huygens-Fresnel Principle ] Born, M; Wolf, E. Principles of Optics $7^{\text {th }}$ (expanded). Cambridge University Press. (1999).

[7] G. Trtnik, F. Kavčič, G.Turk, Prediction of concrete strength using ultrasonic pulse velocity and artificial neural networks, Ultrasonics. 49(1)(2009) 53-60. 
[8] M.A. Kewalramani, R.Gupta, Concrete compressive strength prediction using ultrasonic pulse velocity through artificial neural networks, Auto. Constr., 15(3)(2006) 374-379.

[9] S. Chithra, S.R.R. Senthil Kumar, K. Chinnaraju, F. Alfin Ashmita, A comparative study on the compressive strength prediction models for High Performance Concrete containing nano silica and copper slag using regression analysis and Artificial Neural Networks, Constr. Build. Mater. 114 (2016) 528-536.

[10] B.A. Omran, Q. Chen, R. Jin, Comparison of different data mining techniques for predicting compressive strength of environmentally friendly concrete, J. Comput. Civil. Eng. 30 (6) (2016), DOI: 10.1061/(ASCE)CP.1943-5487.0000596.

[11] Ł. Sadowski, J. Hoła, S. Czarnecki, Non-destructive neural identification of the bond between concrete layers in existing elements, Constr. Build. Mater. 127 (2016) 49-58.

[12] B. Wang, T. Man, H. Jin. Prediction of expansion behavior of self-stressing concrete by artificial neural networks and fuzzy inference systems, Constr. Build. Mater. 84 (2015) 184-191.

[13] Y. Wang, Y. Shao, M.D.Matovic, J.K.Whalen, Recycling combustion ash for sustainable cement production: A critical review with data-mining and time-series predictive models, Constr. Build. Mater. 123 (2016) 673-689.

[14]M. Velay-Lizancos, J.L. Perez-Ordoñez, I. Martinez-Lage, P. Vazquez-Burgo, Analytical and genetic programming model of compressive strength of eco concretes by NDT according to curing temperature, Constr. Build. Mater. 144 (2017) 195-206.

[15] A, Feio, J.S. Machado, In-situ assessment of timber structural members: Combining information from visual strength grading and NDT/SDT methods - A review, Constr. Build. Mater. 101 (2016) 1157-1165.

[16] W. Yeih, R. Huang, Detection of the corrosion damage in reinforced concrete members by ultrasonic testing, Cem. Con. Res. 28(7) (1998) 1071-1083. 
[17] Y. Zhao, W. Jin, Chapter 6 - Rust Distribution in Corrosion-Induced Cracking Concrete, In Steel Corrosion-Induced Concrete Cracking, Butterworth-Heinemann, (2016) 93-109

[18] Y. Zhao, W. Jin, Chapter 9 - Development of Corrosion Products-Filled Paste at the Steel-Concrete Interface, In Steel Corrosion-Induced Concrete Cracking, Butterworth-Heinemann, (2016) 147-158,

[19] Y. Zhao, B. Hu, J. Yu, Non-uniform distribution of rust layer around steel bar in concrete, Corro. Sci. 53(12) (2011) 4300-4308.

[20] Z. Zhang, P. Qiu, Ultrasonic application in concrete property evaluation, 2006, Chemical Industry Publisher, Beijing (in Chinese)

[21] B. D. Liu, W.J. Lv, L. Li, P. F. Li, Effect of moisture content on static compressive elasticity modulus of concrete, Constr. Build. Mater. 69 (2014) 133-142.

[22] B. Lyes Bal, B.B. François, Artificial neural network for predicting drying shrinkage of concrete, Constr. Build. Mater. 38 (2013) 248-254.

[23] NeuroSolutions. NeuroSolutions tutorials. 2015. Available via < http://www.neurosolutions.com/neurosolutions/help/index.html?NeuroSolutionsTutorials.htm 1>, accessed on Sep 12 2016.

[24] D. Zohra, Z. Mehdi Sbartaï, C. Arnaud, G. Fouad, Artificial neural network model for steel-concrete bond prediction, Eng. Struc. 31 (8) (2009)1724-1733,

[25] M. Uysal, H. Tanyildizi, Estimation of compressive strength of self compacting concrete containing polypropylene fiber and mineral additives exposed to high temperature using artificial neural network, Constr. Build. Mater., 27 (1) (2012) 404-414,

[26] M. Uysal, H. Tanyildizi, Predicting the core compressive strength of self-compacting concrete (SCC) mixtures with mineral additives using artificial neural network, Constr. Build. Mater. 25 (11) (2011) 4105-4111.

[27] L. Sadowski, Non-destructive investigation of corrosion current density in steel reinforced concrete by artificial neural networks, Archives of Civil and Mechanical Engineering. 13(1)(2013) 104-111. 
[28] M. Buscema, Back propagation neural networks, Substance use \& misuse, 33(2)(1998) 233-270.

[29] R. Hecht-Nielsen, Theory of the backpropagation neural network, Neural Networks, 1(Supplement-1) (1998) 445-448.

[30] S.A. Billings, G.L. Zheng, Radial basis function network configuration using genetic algorithms, Neural Networks. 8(6)(1995) 877-890.

[31] S. Chen, C.F. Cowan, P.M. Grant, P.M., Orthogonal least squares learning algorithm for radial basis function networks, IEEE Transactions on neural networks, 2(2)(1991) 302-309.

[32] J.S. Chou, N.T. Ngo, W.K. Chong, The use of artificial intelligence combiners for modeling steel pitting risk and corrosion rate, Engineering Applications of Artificial Intelligence. 65 (2017) 471-483.

[33] P. S. Pai, M.T. Mathew, M.M. Stack, L.A. Rocha, Some thoughts on neural network modelling of microabrasion-corrosion processes, Tribology International, 41(7) (2008) $672-681$.

[34] K. Wang, M. Chen, L. Xie, Research on the evolution of bending fatigue and damage of reinforced concrete beams under stray current corrosion, Tiedao Xuebao. 34(11)(2012) 88-93. (in Chinese)

[35] D. Zhang, The application of neural network in the smart optimized control system, Computer Engineering and Design. 14(4)(2008) 8-10. (in Chinese) 